\title{
Emulsifier Supplementation Response in Ross 308 Broilers at 1-10 Days
}

http://dx.doi.org/10.1590/1806-9061-2020-1301

\section{-Author(s)}

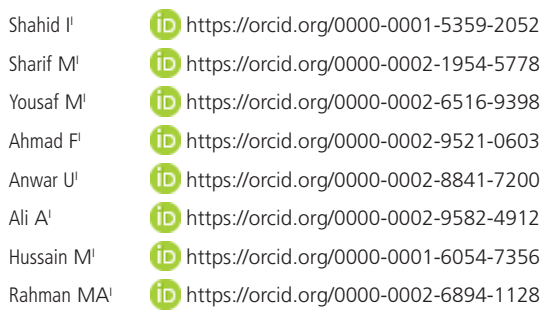

Institute of Animal and Dairy Sciences, University of Agriculture, Faisalabad.

\section{Mail Address}

Corresponding author e-mail address Dr. M. Aziz ur Rahman

Institute of Animal and Dairy Sciences, University of Agriculture, Faisalabad Pakistan

Phone: +92-3341703739

Email: drazizurrahman@uaf.edu.pk

\section{EKeywords}

Emulsifier; Broiler; Starter Phase; Performance.

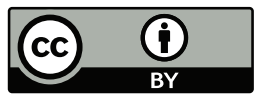

Submitted: 09/April/2020 Approved: 29/June/2020

\section{ABSTRACT}

The study was conducted to check the effect of emulsifier supplementation on growth performance of broiler birds on starter phase, from days 1 to 10 . In the current study, a total of twelve hundred twenty-four Ross 308 broiler one day old chicks were used. Ross 308 broiler chicks were divided into two groups in such a way that each group had12 replicates, and each replicate had 51 birds. The duration of the current trial was of 10 days. Chicks were fed experimental diets with or without emulsifier supplementation. Daily feed intake, body weight, feed conversion ratio and nutrient digestibility were recorded. Mortality was recorded on a daily basis, and feed intake was also corrected for mortality. Data collected from the experiment was interpreted by using analysis of variance method using SPSSTM under Completely Randomized Design. Results showed that emulsifier supplementation improved $(p<0.05)$ feed intake in broiler birds on the $2 \mathrm{nd}, 6^{\text {th }}, 7^{\text {th }}$ and $9^{\text {th }}$ days of the starter phase. Furthermore, emulsifier supplementation $(p<0.05)$ affected the body weight on the $3^{\text {rd }}$ and $10^{\text {th }}$ day of the trial. Emulsifier supplementation also affected $(p<0.05)$ feed conversion ratio on the $10^{\text {th }}$ day of the trial. However, nutrient digestibility was not affected by the supplementation of emulsifier in the diet of broiler chicks. Results showed that emulsifier supplementation should be started on day 10 .

\section{INTRODUCTION}

In broiler production the addition of fat is practiced to increase energy density; however, the digestibility of fat is lower during the starter phase. Low fat digestibility in broiler birds is associated with less production of lipases and bile salts during early life (Jackson et al., 1971; Polin et al., 1980). Due to low bile salts secretion and high fat content in the diet of broiler birds, the supplementation of exogenous emulsifier is recommended (Park et al., 2018). Supplementation of emulsifier increases the active surfaces of fats to allow the lipase activity which breakdown the triglyceride molecules into lipid micelles (Guerreiro Neto et al., 2011). During starter phase broilers have lower fat digestibility due to lower production of bile salts and therefore can affect the final weight of birds (Upadhaya et al., 2017). Therefore, the supplementation of emulsifier in the starter diet can influence the weight in the starter phase and finisher phase of the broiler birds.

Several researchers showed that the supplementation of emulsifiers in the diet of broilers increase fat digestibility and growth rate of broiler (Huang et al., 2007; Zhang et al., 2011; Zaefarian et al., 2015). For example, Zhao et al. (2015) reported that the addition of emulsifiers in the diet of broilers increase fat digestibility. Tan etal. (2016) observed that growth performance increased in broiler supplemented with exogenous emulsifiers in the diet. Bontempo et al. (2018) published that body 
Shahid I, Sharif M, Yousaf M, Ahmad F, Anwar U, Ali A, Hussain M, Rahman MA
Emulsifier Supplementation Response in Ross 308 Broilers at 1-10 Days weight (BW) and feed conversion ratio (FCR) improved in broiler chicks with different levels of emulsifiers in the diet. Similarly, low energy diet supplemented with emulsifier has improved body weight gain (BWG) and FCR in broiler birds (Upadhaya et al., 2017). Likewise, Arif et al. (2016) also published that feed intake (FI), $F C R$, fat digestibility and BW increased in broilers with supplementation of lecithin emulsifier in the diets. However, some researchers reported that the inclusion of emulsifier in broilers diets had no effect on broiler performance (Zhang et al., 2011; Zhao et al., 2015; Upadhaya et al., 2016; Upadhaya et al., 2017). Siyal et al. (2017) concluded that emulsifier supplementation (ES) in the diet improved BW and Fl but did not show any effect on FCR. Likewise, Serpunja \& Kim (2018) revealed that ES in low energy diets did not show any effect on BWG, FI and FCR in the starter and grower as well as in the finisher phase due to less fat in the broiler's diet.

Previous studies were conducted on ES during the whole life (starter, grower, finisher) of the broiler birds with a control diet (Dabbou et al., 2019; Serpunja \& Kim, 2019). But to best of our knowledge, no study has been conducted so far to evaluate the effect of ES during 1-10 days (starter phase) only with control diet and daily monitoring of its effect on growth performance of broiler birds. Therefore, a study was planned to determine the effect of exogenous ES in the diet on growth performance during 1-10 days only in broilers.

\section{MATERIAL AND METHODS}

This study was executed at the Research and Development Farm of Shamim Feed Mills Samma Satta Link Road, Bahawalpur (Pvt. Ltd.).

\section{Experimental design, animal husbandry and experimental diets}

The study was carried out in a Completely Randomized Design with or without ES in the starter diet. A total of 1224 day old Ross broiler were used for this experiment. Experimental chicks were procured from a local hatchery. Total birds were divided into two experimental groups in such a way that each group replicated for twelve times with fifty-one birds in each replicate. The duration of the experimental trial was 10 days. Starter diets were formulated with emulsifier (lyso-phospholipids) and without emulsifier. All the ingredients used in the formulation of the experimental diets were provided by a commercial feed mill (Shamim Feed Mills Bahawalpur, Pakistan). The ingredients used in the diet formulation were taken from the Brazilian table for Poultry and Swine. All diets were formulated on digestible amino acids basis keeping lysine as the reference amino acid as described in a recent study (Abdullah et al. 2019). For the experiment, a total of 24 pens were used with the dimensions of $9.2 \times$ $4.2 \times 2.5$ cubic feet per pen. Rice husk was used as litter material for the bedding of the birds. Light was provided for 24 hours. Automatic nipple drinkers were used for the provision of fresh clean portable water in each pen. All the facilities were the same in each pen. The temperature of the room was $35-33^{\circ} \mathrm{C}$ for the first 3 days, and then it declined $3{ }^{\circ} \mathrm{C}$ weekly. All birds were provided with feed and water ad libitum throughout the starter period. The diets were corn soybean meal based, and formulated to meet or exceed the feeding standard of chicken (Ross manual) requirements. The experimental procedures complied with the guidelines and code of practice of the University of Agriculture, Faisalabad. The experimental protocol was approved by Synopsis Committee University of Agriculture, Faisalabad. Birds were provided with environment free from thrust, freedom of expression of normal behavior and hunger as previously reported in the research of (Aziz ur Rahman et al., 2017; Rahman et al., 2019).

\section{Growth Performance and Nutrient Digestibility}

Feed intake was recorded on the daily basis by subtracting the amount of ort (refusal) from the amount of feed offered. Daily Fl was corrected for mortality.

Feed intake $=$ Daily feed intake - Ort

Body weight was recorded on a daily basis by weighing balance. For that weighing of all birds of one replicate collectively and then dividing it by the number of birds to get average BW of the birds. Blood serum lipid profile was determined following the procedure of previous studies (Dong et al. 2019; He et al. 2018; Su et al. 2013). Feed conversion ratio was calculated on a daily basis by dividing $\mathrm{FI}$ to BW of the birds and was corrected for mortality. Feed conversion ratio was calculated by the equation below:

$$
\text { Feed conversion ratio }=\frac{\text { Feed intake }}{\text { Body weight }}
$$

Nutrient digestibility (dry matter (DM), crude protein (CP) and ether extract (EE)) was calculated. For this purpose celite was used as marker and mixed at the rate of $1 \%$ of feed in the feed from day 7 to day 10 of the trial. For the collection of feces a polythene sheet was spread in each pen. Fecal samples were 
Table 1 - Ingredient and nutrient composition $(\mathrm{g} / \mathrm{kg})$ of diets.

\begin{tabular}{|c|c|c|c|}
\hline Ingredients & Starter & Grower & Finisher \\
\hline Corn $\left({ }^{1}\right.$ CP $\left.7.5 \%\right)$ & 51.96 & 55.64 & 56.38 \\
\hline Soybean meal (CP 45\%) & 35.96 & 26.04 & 18.41 \\
\hline Canola meal (CP 38\%) & 5 & 10 & 15 \\
\hline Tallow & 2.5 & 3.8 & 5.4 \\
\hline Mono-dicalcium phosphate & - & 1.2 & 1.1 \\
\hline Dicalcium phosphate & 1.5 & - & - \\
\hline Limestone & 1.15 & 1.3 & 1.2 \\
\hline L-lysine & 0.43 & 0.5 & 0.74 \\
\hline DL-Methionine & 0.41 & 0.41 & 0.51 \\
\hline L-Threonine & 0.19 & 0.2 & 0.32 \\
\hline L-Tryptophan & - & 0.01 & 0.04 \\
\hline $\mathrm{NaHCO}_{3}$ & 0.1 & 0.1 & 0.1 \\
\hline Salt & 0.3 & 0.3 & 0.3 \\
\hline${ }^{2}$ Vitamin premix & 0.2 & 0.2 & 0.2 \\
\hline${ }^{3}$ Mineral premix & 0.2 & 0.2 & 0.2 \\
\hline Choline & 0.1 & 0.1 & 0.1 \\
\hline Total & 100 & 100 & 100 \\
\hline \multicolumn{4}{|l|}{ Chemical Composition } \\
\hline Metabolizable Energy (kcal/kg) & 3000 & 3100 & 3200 \\
\hline $\mathrm{CP}(\%)$ & 23.76 & 21.28 & 19.98 \\
\hline Crude Fat (\%) & 4.82 & 6.31 & 8.02 \\
\hline Lysine (\%) & 1.5 & 1.28 & 1.25 \\
\hline Methionine (\%) & 0.72 & 0.66 & 0.71 \\
\hline Phosphorous (\%) & 0.45 & 0.42 & 0.4 \\
\hline Calcium (\%) & 0.92 & 0.84 & 0.8 \\
\hline \multicolumn{4}{|c|}{ Emulsifier Lysoforte Extend (Lyso-phospholipids) @ 500 g/ton } \\
\hline
\end{tabular}

${ }^{1}$ Crude protein, 2Vitamin mixture MNVIT-96 supplies (per kilogram of mixture): $5,600,000$ IU vitamin A (acetate), 1,760,000 IU vitamin D3 \(cholecalciferol), 16,800 IU vitamin $\mathrm{E}$ (acetate), $0.7 \mathrm{~g}$ menadione dimethyl pyrimidinol bisulfite, $3.2 \mathrm{~g}$ riboflavin, $6.4 \mathrm{~g}$ d-calcium pantothenate, $36 \mathrm{~g}$ niacin, $7.2 \mathrm{mg}$ vitamin B12, $0.7 \mathrm{~g}$ folic acid, 2.0 $\mathrm{g}$ pyridoxine, and $80 \mathrm{mg}$ biotin, 3Mineral premix: $\mathrm{Mn}, 88 \mathrm{mg} ; \mathrm{Cu}, 66 \mathrm{mg} ; \mathrm{Fe}, 8.5 \mathrm{mg}$; $\mathrm{Zn}, 88 \mathrm{mg} ; \mathrm{Se}, 0.30 \mathrm{mg} / \mathrm{kg}$.

collected after every 24 hours on the polythene sheets. The samples were placed carefully in sampling bags as described in recent studies (lamam-ul-Haq et al. 2019; Shahzad et al. 2019). After sample collection, sample was made free from contaminants such as feathers, down, and scales. Three days samples were mixed and composite sample was obtained for the determination of nutrient digestibility. The sample was dried in the oven at $65^{\circ} \mathrm{C}$ and grinded. After grinding the sample was passed through a $0.5 \mathrm{~mm}$ sieve and preserved for further analysis as reported by (Hussain et al. 2018). Then, the litter material was removed from the sample to avoid the error then this sample was used for the determination of $D M, C P, E E$, ash and acid insoluble ash present in the feces as well as in the feed sample. Procedures used for the analysis was as described by the AOAC (2000) with some modification as described in literature (Muhammad et al. 2016; Niu et al. 2017; Xia et al. 2018).
Digestibility was calculated from the following equation:

Digestibility \% $=100-(100 * \%$ marker in feed $\times \%$ nutrient in feces) $\times 100 \%$ marker in feces $\times \%$ nutrient in feed

\section{Statistical Design}

Data were analysed by ANOVA using the General Linear Model procedures of SPSSTM (SPSS v10.0, 1995) under Completely Randomized Design and mean values were compared using Tukey's Test.

\section{RESULTS}

The effect of ES on $\mathrm{Fl}$ in the diet of broilers during 1-10 days is shown in table 2 . The results showed that ES has significant effect on FI. On day 1 there was no effect ( $p>0.05$ ) of ES on FI. On day 2 there was effect $(p<0.05)$ of $\mathrm{ES}$ on $\mathrm{Fl}$. On day $3 \mathrm{FI}$ was not affected ( $p>0.05$ ) by ES. Similarly, on days $4,5,8$ and 10 of the trial there was no effect ( $p>0.05)$ of ES on Fl. However, numerical values for $\mathrm{Fl}$ on days 3, 4, 5, 8 and 10 of the trial showed greater values for the diet with ES rather than without supplementation. On day 6, 7 and 9 of the trial ES affects the FI $(p<0.05)$.

Table 2 - Effect of emulsifier on Feed intake of broiler in starter phase.

\begin{tabular}{lcccc}
\hline Days & With Emulsifier & Without Emulsifier & 'SEM & ${ }^{2} p$ Value \\
\hline Day 1 & 11.3 & 10.689 & 0.28 & 0.137 \\
Day 2 & $14.79^{\mathrm{a}}$ & $14.25^{\mathrm{b}}$ & 0.21 & 0.018 \\
\hline Day 3 & 18.52 & 17.88 & 0.33 & 0.189 \\
\hline Day 4 & 21.16 & 20.5 & 0.3 & 0.133 \\
\hline Day 5 & 25.18 & 25.28 & 0.32 & 0.825 \\
Day 6 & $29.77^{\mathrm{a}}$ & $29^{\mathrm{b}}$ & 0.21 & 0.017 \\
Day 7 & $33.67^{\mathrm{a}}$ & $32.82^{\mathrm{b}}$ & 0.25 & 0.03 \\
Day 8 & 37.82 & 37.3 & 0.23 & 0.13 \\
Day 9 & $42.808^{\mathrm{a}}$ & $41.99^{\mathrm{b}}$ & 0.28 & 0.05 \\
Day 10 & 46.505 & 46.045 & 0.37 & 0.3 \\
\hline
\end{tabular}

'Standard error of the mean of 12 replicates; ${ }^{2} a$, b Means with different superscripts within a row differ significantly $(p<0.05)$.

The effect of emulsifier on BW in the diet of broilers during 1-10 days is shown in table 3 . Results showed that on day 1 and 2 of the trial there was no effect $(p>0.05)$ of ES on BW. However, numerical values showed greater values for diet with ES. On day 3 there was effect $(p<0.05)$ of ES on BW. Results showed that ES on day $4,5,6,7,8$ and 9 of the trial has no effect on BW. Numerical values for day 4, 5, 6, 7, 8 and 9 of the trial were greater for the diet with ES. On day 10 of the trial there was effect $(p<0.05)$ of ES on BW. The effect of the emulsifier on FCR in the diet during 1-10 
Table 3 - Effect of emulsifier on Body weight of broiler in starter phase.

\begin{tabular}{lcccc}
\hline Days & With Emulsifier & Without Emulsifier & ${ }^{1}$ SEM & ${ }^{2} p$ Value \\
\hline Day 1 & 49.68 & 48.22 & 0.35 & 0.367 \\
\hline Day 2 & 62.57 & 62.11 & 0.62 & 0.6 \\
Day 3 & $79.03^{\mathrm{a}}$ & $76.87^{\mathrm{b}}$ & 0.59 & 0.017 \\
Day 4 & 97.39 & 96.9 & 0.67 & 0.18 \\
Day 5 & 119.1 & 117.6 & 1.13 & 0.35 \\
Day 6 & 140.64 & 138.96 & 1.4 & 0.404 \\
Day 7 & 162.98 & 160.81 & 1.43 & 0.3 \\
Day 8 & 188.74 & 185.63 & 1.59 & 0.18 \\
Day 9 & 216.5 & 211.88 & 1.73 & 0.07 \\
Day 10 & $244.86^{\mathrm{a}}$ & $238.22^{\mathrm{b}}$ & 2.04 & 0.03 \\
\hline
\end{tabular}

${ }^{1}$ Standard error of the mean of 12 replicates, ${ }^{2} a$, b Means with different superscripts within a row differ significantly $(p<0.05)$.

days is shown in table 4 . Table showing that ES has no effect $(p>0.05)$ on FCR on day 1 of the trial. Similarly, on day $2,3,4,5,6,7,8$ and 9 of the trial there was no effect of ES on FCR. However, means of replicates on day $1,2,3$ and 4 of the trial showed improved values of FCR numerically with ES. On day 10 of the trial there was effect $(p<0.05)$ of ES on FCR.

Table 4 - Effect of emulsifier on Feed conversion ratio of broiler in starter phase.

\begin{tabular}{lcccc}
\hline Days & With Emulsifier & Without Emulsifier & 'SEM & ${ }^{2} p$ Value \\
\hline Day 1 & 0.23 & 0.21 & 0.006 & 0.226 \\
\hline Day 2 & 0.24 & 0.23 & 0.004 & 0.09 \\
Day 3 & 0.24 & 0.23 & 0.005 & 0.76 \\
Day 4 & 0.22 & 0.21 & 0.004 & 0.47 \\
Day 5 & 0.21 & 0.22 & 0.003 & 0.41 \\
Day 6 & 0.21 & 0.21 & 0.002 & 0.37 \\
Day 7 & 0.21 & 0.20 & 0.002 & 0.45 \\
Day 8 & 0.20 & 0.20 & 0.002 & 0.81 \\
Day 9 & 0.20 & 0.20 & 0.002 & 0.81 \\
Day 10 & $0.19^{b}$ & $0.19^{a}$ & 0.002 & 0.02 \\
\hline
\end{tabular}

'Standard error of the mean of 12 replicates; ${ }^{2} a$, b Means with different superscripts within a row differ significantly $(p<0.05)$.

The effect of emulsifier on nutrient digestibility in the diet of broilers during 1-10 days is shown in table 5 . Results showed that there was no effect ( $p>0.05)$ of ES on DM, CP and EE digestibility throughout the starter phase (1-10 days).

Table 5 - Effect of emulsifier on nutrient digestibility of broiler in starter phase.

\begin{tabular}{lcccc}
\hline Parameters & $\begin{array}{c}\text { Without } \\
\text { Emulsifier }\end{array}$ & $\begin{array}{c}\text { With } \\
\text { Emulsifier }\end{array}$ & SEM & $p$ Value \\
\hline \% DM Digestibility & 58.47 & 52.72 & 1.92 & 0.06 \\
\% CP Digestibility & 54.38 & 52.63 & 2.62 & 0.61 \\
\% Fat Digestibility & 69.29 & 70.32 & 2.69 & 0.80 \\
\hline
\end{tabular}

'Standard error of the mean of 12 replicates; ${ }^{2} a$, b Means with different superscripts within a row differ significantly $(p<0.05)$.

\section{DISCUSSION}

Fat sources have been utilized to increase energy density of broilers diet (Summer \& Lessons, 2005). Emulsifier supplementation in young age is efficient due to low availability of lipases and bile salts that increase fat utilization and subsequent availability of energy to growing chicks (Jackson et al., 1971; Polin et al., 1980). The current study was executed to check the effect of ES in the diet of broiler chicks on growth performance in starter phase when fat digesting organs are underdeveloped. The results of Fl showed that emulsifier supplementation effects FI significantly. The feed intake of the diet supplemented with emulsifier was higher than in the diet without emulsifier supplementation during 1-10 days of the trial. The results of current studies are in agreement with the results of Bontempo et al. (2018); Drażbo et al. (2019). Park et al. (2018) reported increase in Fl during the starter phase of broilers with the addition of synthetic emulsifier. The increase in $\mathrm{Fl}$ is possibly related with better utilization of the diet by improve the mechanism of digestion due to ES that causes more hunger (Bontempo et al., 2018). The results are in contrast to Arif et al. (2016); Kaczmarek et al. (2015) who stated that emulsifier supplementation had no significant effect on Fl. The results are also contrasting to the findings of Imran et al. (2016) who reported decrease in $\mathrm{Fl}$ with supplementation of emulsifier. The current study revealed that $\mathrm{FI}$ was improved on day 6, 7 and 9, so it is suggested that feed without ES should be fed to broiler chicks for the first five days of life in the starter phase. The results of BW showed significant $(p<0.05)$ effect of ES at day 3rd and 10th of the starter phase. Emulsifier supplementation improves the digestion of fat at younger ages and increases availability of energy. This increase in energy availability causes energy deposition in the form of body fat and muscle glycogen and better body confirmation, but this was not the case in this study. However, weight gain may be greater due to more Fl with ES as shown in table 2 . The results of the current study are in agreement with the results of Bontempo et al. (2018) who reported increase in BW due to emulsifier supplementation. These results are not in line with the results of Park et al. (2018); Serpunja \& Kim (2019) who reported no effect of ES on BW of broiler birds. In the same way, Tan et al. (2016) reported that ES in the starter phase has no significant effect on BW. The results are also contrasting with the results of Arif et al. (2016) who reported decrease of BW with 
the supplementation of emulsifier. The results of FCR showed improvement with the supplementation of emulsifier on day 10 th of the trial. This improvement in FCR is reflecting increase in weight gain as compared to $\mathrm{Fl}$. The results of current studies are in agreement with the results of Drażbo et al. (2019); Allahyari-Bake \& Jahanian (2017), who reported improvement in FCR with emulsifier supplementation. Contrasting to the findings of current studies Ho Cho et al. (2012); Arif et al. (2016) showed that ES had no significant effect on FCR. The results of nutrient digestibility showing that ES has no significant effect on digestibility of $D M, C P$ and EE through starter phase (1-10 days). The results of current studies are in agreement to results of Allahyari-Bake \& Jahanian (2017), they reported no effect of emulsifier addition on nutrient digestibility except to that of EE. Generally, gut health is considered important for better digestibility and performance in livestock (Qiu et al. 2019a; Qiu et al. 2019b) and external feed additives are provided to improve the gut health and performance of livestock. However, in the current study, we did not find ES effect on EE digestibility. In contrast, Arif et al. (2016) reported improvement in DM, CP and EE digestibility with ES. Similarly, Drażbo et al. (2019) reported increase in digestibility of fat with supplementation of emulsifier.

\section{CONCLUSION}

In conclusion, the results of the current study showed that emulsifier supplementation in broiler diets in the starter phase (1-10 days) have positive effect on BW, $\mathrm{FI}$ and FCR but had no significant effect on nutrient digestibility. Based on the results, it is suggested that broiler chicks should be fed diet without ES for the first 9 days of the starter phase when there is no effect on BW and FCR. Furthermore, from day 10 ES should be added in broiler chicks diets as there was significant effect on BW and FCR.

\section{REFERENCES}

Abdullah, HM, Bielke LR, Helmy YA. Effect of arginine supplementation on growth performance and immunity of broilers: a review. Journal of Global Innovation in Agricultural and Social Sciences 2019;7(4):141144

Allahyari-Bake S, Jahanian R. Effects of dietary fat source and supplemental lysophosphatidylcholine on performance, immune responses, and ileal nutrient digestibility in broilers fed corn/soybean meal or corn/wheat/ soybean meal based diets. Poultry Science 2017;96:1149-1158.

Arif M, Abbas MT, Saeed M, Reyad ul Ferdous M, Hassan MA, Arain MA, et al. Emulsifier effect on fat utilization in broiler chicken. Asian Journal of Animal and Veterinary Advances 2016;11:158-167.
Aziz ur Rahman M, Chuanqi X, Huawei S, Binghai C. Effects of hay grass level and its physical form (full length vs. chopped) on standing time, drinking time, and social behavior of calves. Journal of Veterinary Behavior: Clinical Applications and Research 2017;21(Supplement C):7-12.

Bontempo V, Comi M, Jiang XR, Rebucci R, Caprarulo V, Giromini C, et al. Evaluation of a synthetic emulsifier product supplementation on broiler chicks. Animal Feed Science and Technology 2018;240:157-164.

Dabbou S, Schiavone A, Gai F, Martinez S, Madrid J, Hernandez F, et al. Effect ofdietary globin, a natural emulsifier, on the growth performance and digestive efficiency of broiler chickens. Italian Journal of Animal Science 2019;18:530-537.

Dong C, Yuanwei C, Huabing Z, Kequan X, Jing T, Qiyuan T, et al. Effects of replacing whole-plant corn silage with whole-plant rice silage and rice straw on growth performance, apparent digestibility and plasma parameters in growing angus cross bred beef cattle. International Journal of Agriculture and Biology. 2019;22:1116-1122

Drażbo A, Kozłowski K, Croes E. The effect of emulsifier on growth performance and fat digestibility in turkeys. Annals of Animal Science 2019;19:421-431.

Guerreiro Neto ACG, Pezzato AC, Sartori JR, Mori C, Cruz VC, Fascina VB, et al. Emulsifier in broiler diets containing different fat sources. Brazilian Journal of Poultry Science 2011;13:119-125

He Y, Niu W, Qiu Q, Xia C, Shao T, Wang H, et al. Effect of calcium salt of long-chain fatty acids and alfalfa supplementation on performance of Holstein bulls. Oncotarget 2018;9(3):3029

Huang J, Yang D, Wang T. Effects of replacing soy-oil with soy-lecithin on growth performance, nutrient utilization and serum parameters of broilers fed corn-based diets. Asian Australasian Journal of Animal Sciences 2007;20(12):1880

Hussain S, Khan AA, Shakoor A, Goheer A, Qadir T, Khan MM, et al. Effect of cold and heat stress on different stages of wheat: a review. The Journal of Global Innovations in Agricultural and Social Sciences. 2018;6(4):123-128.

Ho Cho J, Zhao P, Kim IH. Effects of emulsifier and multi enzyme in different energy density diet on growth performance, blood profiles, and relative organ weight in broiler chickens. Journal of Agriculture Science 2012;4(10):161-168.

lamam-ul-Haq, Naeem MS, Amir RM, Ilyas M, Shabir F, Ahmad I, et al. Growth and yield response of spring maize (zea mays I.) Under different potassium doses and irrigation regimes. Journal of Global Innovation in Agricultural and Social Sciences 2019;7(3):135-139.

Imran M. Effect of supplemental emulsifier on the utilization of dietary poultry fat in broilers. [thesis]. Faisalabad (PAK): Institute of Animal and Dairy Sciences University of Agriculture Faisalabad Pakistan; 2016.

Jackson BT, Smallwood RA, Piasecki GJ, Brown AS, Rauschecker HF, Lester R. Fetal bile salt metabolism I. The metabolism of sodium cholate $14 \mathrm{C}$ in the fetal dog. The Journal of Clinical Investigation 1971;50:12861294

Kaczmarek SA, Bochenek M, Samuelsson AC, Rutkowski A. Effects of glyceryl polyethylene glycol ricinoleate on nutrient utilisation and performance of broiler chicken. Archives of Animal Nutrition 2015;69:285-296

Muhammad AU, Xia CQ, Cao BH. Dietary forage concentration and particle size affect sorting, feeding behaviour, intake and growth of Chinese holstein male calves. Journal of Animal Physiology and Animal Nutrition 2016;100(2):217-223 
Niu W, He Y, Xia C, Rahman MAU, Qiu Q, Shao T, et al. Effects of replacing Leymus chinensis with whole-crop wheat hay on Holstein bull apparent digestibility, plasma parameters, rumen fermentation, and microbiota. Scientific Reports 2017;7(1):1-12.

Park JH, Nguyen DH, Kim IH. Effects of exogenous lysolecithin emulsifier supplementation on the growth performance, nutrient digestibility, and blood lipid profiles of broiler chickens. Journal of Poultry Science 2018;55:190-194.

Polin D, Wing TL, KI P, Pell KE. The effect of bile acids and lipase on absorption of tallow in young chicks. Poultry Science 1980;59:27382743.

Qiu Q, Gao C, Gao Z, He Y, Cao B, Su H. Temporal dynamics in rumen bacterial community composition of finishing steers during an adaptation period of three months. Microorganisms 2019a;7(10):410.

Qiu Q, Zhu Y, Qiu X, Gao C, Wang J, Wang H, et al. Dynamic variations in fecal bacterial community and fermentation profile of Holstein steers in response to three stepwise density diets. Animals 2019b;9(8):560.

Rahman MA, Qi XC, Binghai C. Nutrient intake, feeding patterns and abnormal behavior of growing bulls fed different concentrate levels and a single fiber source (corn stover silage). Journal of Veterinary Behaviour 2019;33:46-53.

Serpunja S, Kim IH. The effect of sodium stearoyl-2-lactylate (80\%) and tween $20(20 \%)$ supplementation in low-energy density diets on growth performance, nutrient digestibility, meat quality, relative organ weight, serum lipid profiles and excreta microbiota in broilers. Poultry Science 2018;98:269-275.

Shahzad M, Ghani WH, Ayyub M, Ali Q, Ahmad HM, Faisal M, et al. Performance of some wheat cultivars against aphid and its damage on yield and photosynthesis. Journal of Global Innovation in Agricultural and Social Sciences 2019;7(3):105-109.

Siyal FA, Wang T, Ezzat Abd M, Alagawany M, Wang C, Wan X, et al. Effect of soy lecithin on growth performance, nutrient digestibility and hepatic antioxidant parameters of broiler chickens. International Journal of Pharmacology 2017;13:396-402.
Su H, Wang Y, Zhang Q, Wang F, Cao Z, Rahman MAU, et al. Responses of energy balance, physiology, and production for transition dairy cows fed with a low-energy prepartum diet during hot season. Tropical Animal Health and Production. 2013;45(7):1495-1503.

Tan HS, Zulkifli I, Farjam AS, Goh YM, Croes E, Partha SK, et al. Effect of exogenous emulsifier on growth performance, fat digestibility, apparent metabolisable energy in broiler chickens. Journal of Biochemistry, Microbiology and Biotechnology 2016;4:7-10.

Upadhaya SD, Lee JS, Jung KJ, Kim IH. Influence of emulsifier blends having different hydrophilic lipophilic balance value on growth performance, nutrient digestibility, serum lipid profiles, and meat quality of broilers. Poultry Science 2018;97:255-261.

Upadhaya SD, Park JW, Park JH, Kim IH. Efficacy of 1,3-diacylglycerol as a fat emulsifier in low-density diet for broilers. Poultry Science 2017;96:1672-1678.

Xia C, Liang Y, Bai S, He Y, Muhammad AUR, Su H, et al. Effects of harvest time and added molasses on nutritional content, ensiling characteristics and in vitro degradation of whole crop wheat. Asian-Australasian Journal of Animal Sciences 2018;31:354-362.

Zaefarian F, Romero LF, Ravindran V. Influence of high dose of phytase and an emulsifier on performance, apparent metabolisable energy and nitrogen retention in broilers fed on diets containing soy oil or tallow. British Poultry Science 2015;56(5):590-597.

Zhang B, Haitao L, Zhao D, Guo Y, Barri A. Effect of fat type and lysophosphatidylcholine addition to broiler diets on performance, apparent digestibility of fatty acids, and apparent metabolizable energy content. Animal Feed Science and Technology 2011;163:177-184.

Zhao PY, Kim IH. Effect of diets with different energy and lysophospholipids levels on performance, nutrient metabolism, and body composition in broilers. Poultry Science 2017;96:1341-1347. 